Article

\title{
Development of Climate Indices Using Local Weather Data for Shading Design
}

\section{Dong-Seok Lee ${ }^{1}$, Jae-Hun Jo ${ }^{1, *}$, Sung-Han Koo ${ }^{2, *}$ and Byung-Yun Lee ${ }^{3}$}

1 Department of Architectural Engineering, Inha University, Incheon 151-402, Korea;

E-Mail: dslee3010@gmail.com

2 BRE Global, Bucknalls Lane, Garston, Watford WD25 9XX, UK

3 Department of Architecture, Chungbuk National University, Cheongju 361-763, Korea;

E-Mail: ecoville@cbnu.ac.kr

* Authors to whom correspondence should be addressed; E-Mails: jhjo@inha.ac.kr (J.-H.J.); koosh@bre.co.uk (S.-H.K.); Tel.: +82-32-860-7582 (J.-H.J.); +44-1923-664-568 (S.-H.K.); Fax: +82-32-866-4624 (J.-H.J.).

Academic Editor: Marc A. Rosen

Received: 3 December 2014 / Accepted: 27 January 2015 / Published: 10 February 2015

\begin{abstract}
The energy performance of buildings depends on how effectively the building envelope responds to climate. Architects, therefore, need to design building envelopes with the consideration of local climate characteristics in the early design stage. Simplified formulas were used that evaluate the heating and cooling energy demand of building envelopes, which were applied to a model building with envelope and climate properties according to eight climate zones. Two climate indices, $P$ and $S$, were developed. $P$ enables the comparison of the heating and cooling energy demand of building envelopes, and $S$ is for comparing the solar heat gain during heating and cooling seasons to review the feasibility of installing shading devices. The physical properties of envelopes were set differently according to the requirements in each climate zone proposed by American Society of Heating, Refrigerating and Air-Conditioning Engineers (ASHRAE) 90.1. Using local climate data, the $P$ and $S$ of 24 cities over eight climate zones in the United States were derived, which can be used to evaluate the heating and cooling energy characteristics of envelopes. The indices not only enable users to understand the characteristics of the local climate conditions in a simple manner, but also to carry out quantitative assessments on whether shading devices are feasible and, if so, what type is recommended.
\end{abstract}


Keywords: climate index; building envelope; shading device; heating and cooling energy

\section{Introduction}

Buildings consume energy in the process of responding to the outdoor weather conditions. The impact of climate factors, such as solar radiation, ambient temperature and humidity, is transferred through the building envelope and affects the internal conditions of the building. The indoor environment and energy performance, therefore, depend hugely on how effectively the building envelope copes with the surrounding climate. In order to maintain a comfortable indoor environment and to improve the energy performance of a building, it is required that the building envelopes be properly designed with the consideration of local weather conditions [1,2].

In general, the weakest parts of the building elements act as a bridge, allowing the outdoor condition to be transferred into the indoor space and, in many cases, these are the windows. Glazing lets solar radiation into the building, unlike walls, and it usually has a higher thermal transmittance property. Even a double-glazed window has a thermal transmittance property of around $3 \mathrm{~W} / \mathrm{m}^{2} \mathrm{~K}$, which is higher than concrete walls, which generally have a value lower than $1 \mathrm{~W} / \mathrm{m}^{2} \mathrm{~K}$. For this reason, external shading devices, which compensate for the windows' weaknesses by controlling solar radiation, are considered to be one of the key elements constituting building envelopes [3].

The parameters governing building envelopes, such as solar absorbance, thermal transmittance and the solar gain factor, can cause a significant impact on the heating and cooling energy demand [4]. Many studies have been carried out in order to understand how buildings can perform better depending on the different types of glazing, window systems or shading devices used.

Evaluations of the performance of certain types of shading devices were carried out. Choi et al. [5] proposed a methodology to evaluate the performance of external shading devices considering the surrounding topography, and Kim et al. [6] compared the cooling demand of a building when different types of external shading devices were installed. Freewan [7] conducted research on the temperature and illuminance level of indoor spaces through a mock-up construction of three kinds of external shadings. David et al. [8] compared the thermal and light environment performance of four different types of overhangs. There was also a study in which an evaluation was carried out on the light and thermal performance, such as the daylighting, shading and heat gain of exterior fixed shadings in local climate conditions [9]. Tzempelikos et al. [10] analysed the energy demand of lighting and heating/cooling from different directions with four design cases, where roll blinds were covering different areas of the windows. Kim et al. [11] conducted analyses on the energy performance in various cases in which the glazing had different heat transfer coefficient values with different solar heat gain coefficients and in which different types of shading devices and lighting systems were installed. They then proposed an energy analysis indicator, which shows the energy consumption according to the complex application of window elements. The thermal performance of shading devices can vary depending on the orientations of buildings and the local climate conditions. In a previous study, four types of shading systems fitted in buildings located in various climate conditions showed different solar gain values [12]. 
In the previous studies [3-12], the indoor environment and energy performance of buildings were analysed using various computer simulation tools, which are based on numerical analysis. The results from these researches can be used when the thermal and light environment performances are evaluated with a building using different types of envelopes and shading devices.

Methodologies were also proposed in many studies that enable the evaluation of energy performance in the early design stages. Picco et al. [13] proposed a methodology to simplify a detailed building model in order to shorten the analysis procedures for building energy simulations. Baker et al. [14] proposed an energy evaluation methodology that enables the evaluation of the annual primary energy need for the thermal performance and the lighting, heating, cooling and ventilating. These methodologies can provide simple and quick measures to estimate the building energy performance; however, they require detailed building modelling or they can only be applied to limited regions with certain climate conditions.

From the designer's point of view, the evaluation of the energy performance of the building envelope can potentially cause changes to the building design, which may require significant effort and time. It is, therefore, essential to carry out the analysis on the local climate conditions with regards to the building energy performance in the early design stage. Examples of local climate data include the Climate Energy Index (CEI) and the Building Energy Index (BEI). CEI and BEI are derived based on weather data around the globe and are able to describe the characteristics of the local climate in the form of the quantitative amount of energy used in buildings. They are, however, calculated based on a psychrometric chart, and they do not consider the elements governing the shapes and the properties of building envelopes [15,16].

In addition, Cooling Degree-Day (CDD) and Heating Degree-Day (HDD) are well-known indices derived from local climate data. These indices are derived based on the outdoor temperature, and they do not consider the elements of building envelopes. Although the indices described above, i.e., CEI, $\mathrm{BEI}, \mathrm{CDD}$ and HDD, can be used to estimate the amount of energy needed in the local climate, the design information they can deliver to architects in the early design stage is limited [17].

The purpose of this study is to develop climate indices that can be used in the early design stage, assisting users with understanding the characteristics of local climates and with making judgment on the feasibility of shading devices. Two indices were developed based on the equations that assess the thermal environment in the aspects of climate factors, external shadings, windows and walls. The heating and cooling energy index, $P$, was developed, which evaluates the amount of heating/cooling energy demand generated by building envelopes in the form of the equivalent amount of primary energy demand. The solar heat gain index, $S$, was developed, which represents the impact of solar radiation by evaluating the solar heat gain (or loss) over both heating and cooling seasons. The indices were then applied to 24 cities in the United States, representing different climate conditions, and provided quantitative assessments on whether shading devices are necessary in those regions and, if so, what type of shadings are recommended.

\section{Scope of Research}

The performance of building envelopes can be assessed from different aspects, such as thermal performance, light, natural ventilation and acoustic environment. The climate factors that affect the 
indoor environment include the outdoor ambient temperature, solar radiation, luminance and wind. The outdoor temperature and solar radiation influence the indoor thermal environment and luminance, i.e., daylight affects the indoor lighting environment. Wind has an impact on natural ventilation and infiltration.

A comfortable indoor environment, therefore, is achieved by mitigating the impact of the climate factors from these aspects. For example, the thermal environment can be improved by utilising or blocking solar radiation and heat transfer through windows and walls by fitting well-insulated materials and by properly designing shading devices. The light environment can be enhanced by controlling the daylight, which is governed by the size and the shape of windows and shading devices. Natural ventilation and air-tightness performance affect the indoor temperature and air quality, and the data are generally obtained by measurements. The indoor environment can also be affected by other factors, such as the urban heat island effect [2], and measures, e.g., cool roofs [18] and cool coatings [19], have been suggested to mitigate this.

In this study, we focused on building envelopes (mainly shadings), which play a major role in achieving a comfortable indoor environment, and only the thermal environment aspect was reviewed. Figure 1 shows the climate factors and elements included in the development of the climate indices described in this paper. The key factors include ambient temperature and solar radiation from the climate perspective, as well as the shading factor, solar heat gain coefficient and the thermal transmittance of windows and walls from the building envelope perspective.

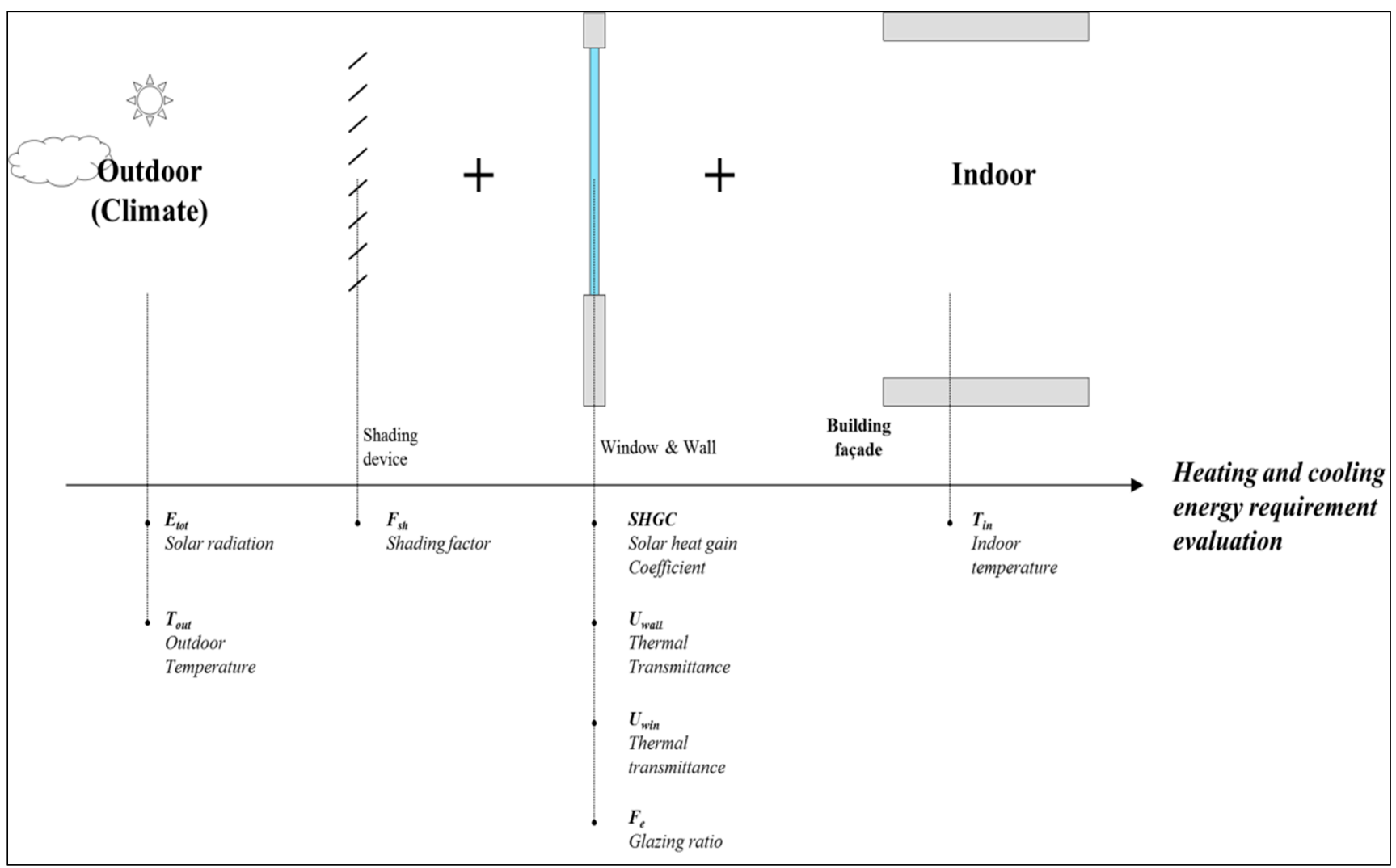

Figure 1. Elements affecting the heating and cooling energy of building envelopes. 
As mentioned in the Introduction, windows are one of the most vulnerable parts of buildings, which let outdoor conditions affect the indoor environment, and shading devices are commonly used to rectify the weaknesses of windows. Depending on where the shadings are fitted and whether they can be adjusted, shading devices can be classified as "external" and "internal", and external shadings can be "fixed" or "movable". External shadings are generally more effective than internal shadings, because they can block the solar radiation outside of the building before it reaches the indoor space. Fixed shading devices are basically horizontal overhangs, vertical fins or egg crates, depending on the direction of the plane or slat. Movable shading devices, on the other hand, can have many types, such as awnings, roll blinds, venetian blinds and aperture, depending on the nature of the movement.

The performance of shading devices can be reviewed not only from thermal environment prospective, but also from other aspects, such as design, light environment or user conditions. It is, however, still difficult to make a judgment on whether shading devices are necessary at the early design stage unless the users spend much time and effort understanding the local climate conditions and the energy demand generated due to these. In this study, the intention was to focus on the thermal environment by controlling solar irradiation and enabling users to review the necessity of shading devices by carrying out qualitative assessments using the indices. The indices developed in this paper, therefore, are to provide simplified information to the users about the local climate conditions and solar radiation in order to facilitate making a judgement on whether shading devices are feasible in a specific region.

\section{Development of Indices}

Development of the climate indices was carried out in four stages. First, the energy demand generated by the building envelopes was identified and calculated. Because different systems can be used for heating and cooling, respectively, the system efficiency coefficient was derived, so that the amount of energy demand can be expressed in the form of the equivalent amount of primary energy. A model building was defined, parameters related to building envelopes were applied to the equations and, finally, the $P$ and $S$ indices were developed.

\subsection{Heat Transfer through Building Envelopes}

The daily average solar radiation received by building envelopes from different directions and the ambient temperature are the two key elements required in the calculation of the heat and cooling energy demand of building envelopes. Heat transfer through the building envelope, therefore, can be described by three aspects, i.e., solar radiance through glazing and conductive heat transmission through windows and walls. Each type of heat transfer can vary significantly depending on the local climate conditions. For the estimation of these heat transfer types, the calculation methodology described in ISO 18292 [20] was chosen. In order to consider the shape of the building envelopes and to reflect the seasons, the glazing ratio $\left(F_{e}\right)$, cooling day $(C D)$ and heating day $(H D)$ were additionally applied. $C D$ (or $H D$ ) is calculated by adding up the number of days when the daily average outdoor temperature $\left(T_{\text {out }}\right)$ is higher (or lower) than the indoor set temperature $\left(T_{\text {in }}\right)$.

The amount of heat transfer through windows generated by solar radiance can be calculated as follows: 


$$
\begin{aligned}
& q_{\mathrm{c}, \mathrm{sol}}=A F_{\mathrm{e}} E_{\mathrm{tot}} S H G C F_{\mathrm{sh}} \frac{24 C D}{1000} \\
& q_{\mathrm{h}, \mathrm{sol}}=A F_{e} E_{\mathrm{tot}} S H G C F_{\mathrm{sh}} \frac{24 H D}{1000}
\end{aligned}
$$

The amount of conductive heat transfer through windows and walls due to the temperature difference between the indoors and outdoors is calculated as below:

$$
\begin{gathered}
q_{\mathrm{c}, \text { win }}=A F_{\mathrm{e}} U_{\text {win }}\left(T_{\text {out }}-T_{\mathrm{in}}\right) \frac{24 C D}{1000} \\
q_{\mathrm{h}, \text { win }}=A F_{\mathrm{e}} U_{\text {win }}\left(T_{\text {out }}-T_{\mathrm{in}}\right) \frac{24 H D}{1000} \\
q_{\mathrm{c}, \text { wall }}=A\left(1-F_{\mathrm{e}}\right) U_{\text {wall }}\left(T_{\text {out }}-T_{\text {in }}\right) \frac{24 C D}{1000} \\
q_{\mathrm{h}, \text { wall }}=A\left(1-F_{\mathrm{e}}\right) U_{\text {wall }}\left(T_{\text {out }}-T_{\text {in }}\right) \frac{24 H D}{1000}
\end{gathered}
$$

The energy demand generated by building envelopes is expressed in kilowatt hours $(\mathrm{kWh})$ and can be estimated by calculating the heat gain (or loss) through building envelopes. During the "cooling days", the amount of radiant heat transfer generated by direct sunlight and the conductive heat transfer through glazing and walls are calculated and are considered to be the "heat gain". During the "heating days", the difference between the conductive heat transfer through envelopes and the radiant heat transfer by daylight is calculated and is to be considered as the "heat gain" or "heat loss", depending on the value.

\subsection{Applying System Efficiency}

Although the energy demands generated by building envelopes over cooling days and heating days, calculated above, have the same unit, i.e., kilowatt hours, the impact of them cannot be compared with each other. This is because different systems are used in cooling days and heating days, respectively, and each system has different efficiency, as they use various types of resources [21,22]. For example, electricity is mostly used for cooling, while gas, coal and oil can be used for heating. Therefore, even though the same amount of energy demand is generated by the building envelopes in each season, the actual energy demand to compensate for them may be different between cooling days and heating days.

The energy demand generated by building envelopes, therefore, was converted to the equivalent amount of primary energy to facilitate the comparison between energy demands in different seasons. In order to do this, the energy demand was first converted to "energy consumption" using a typical type of system. For cooling days, it was assumed that the building is cooled by an electric heat pump (EHP) with a coefficient of performance (COP) value of three. As COP commonly has a value between two and 4.5, the EHP chosen in this study represents a typical system. For heating days, it was assumed that the building uses a gas boiler. Boiler efficiency can vary depending on the type of system, such as condensing, high efficiency or conventional boilers. It was assumed that the building is fitted with a high efficiency boiler, which has an efficiency of $80 \%$ when the boiler load reaches $50 \%$. Then, this was converted to "primary energy" using the conversion factors. The conversion factors for primary energy can vary depending on the type of energy sources, such as nuclear, wind, hydro, and so 
on. In this study, the primary energy conversion factors were set as "fossil fuels". For cooling days, the conversion factor we used was 3.0 and 1.1 for heating days [23].

Therefore, the factors to convert the energy demand to primary energy were $1.0\left(=3^{-1} \times 3.0\right)$ for cooling energy demand and $1.375\left(=0.8^{-1} \times 1.1\right)$ for heating energy demand. By applying these factors to Equations (1)-(6) above, the primary energy can be calculated.

\subsection{Setting Building Envelope Properties}

The equations described in the previous sections contain parameters related to the building, i.e., wall area $(A)$, glazing ratio $\left(F_{\mathrm{e}}\right)$, shading factor $\left(F_{\mathrm{sh}}\right)$, solar heat gain coefficient $(S H G C)$, thermal transmittance of windows and walls ( $U_{\text {win }}$ and $\left.U_{\text {wall }}\right)$ and indoor temperature $\left(T_{\text {in }}\right)$, which can be defined if a generic model building is established. An office building with $1 \mathrm{~m}^{2}$ of envelope area at the orientations of south, west, north and east was set as a model building, i.e., $A=1$. Shading devices were not installed, as the model building is for reviewing the shading requirement; therefore, $F_{\text {sh }}=1$. Indoor temperature was set as $24{ }^{\circ} \mathrm{C}$ for cooling and $18{ }^{\circ} \mathrm{C}$ for heating. The rest of the parameters, i.e., $S H G C, U_{\text {win }}$ and $U_{\text {wall, }}$, were defined differently based on where the model building is located, according to non-residential building data in eight climate categories defined in the International Climate Zone described in American Society of Heating, Refrigerating and Air-Conditioning Engineers (ASHRAE) 90.1 [24], as shown in Table 1. The building envelope was set as punched windows, and the glazing ratio was set as $40 \%$ (ASHRAE 90.1 limits the glazing ratio to a maximum of $40 \%$ for punched windows) in order to maximize the effective solar energy, i.e., $F_{\mathrm{e}}=0.4$.

With the pre-defined parameters in place, only the parameters that are related to climate factors, i.e., $E_{\text {tot, }} C D, H D$ and $T_{\text {out, }}$ remain in the equations. Except the conversion factors, the rest of the constants in the equations are governed by the properties of the building envelopes defined according to the International Climate Zone, which are $S H G C, U_{\text {win }}$ and $U_{\text {wall. }}$ By expressing these parameters with a single variant, i.e., $\alpha_{n}, \beta_{n}, \gamma_{n}$, Equations (1), (3) and (5) can be expressed as below.

$$
\begin{gathered}
P_{\mathrm{E}, \mathrm{c}, \mathrm{sol}}=1.0 \alpha_{n} E_{\mathrm{tot}} C D \\
P_{\mathrm{E}, \mathrm{c}, \mathrm{win}}=1.0 \beta_{n}\left(T_{\mathrm{out}}-24\right) C D \\
P_{\mathrm{E}, \mathrm{c}, \mathrm{wall}}=1.0 \gamma_{n}\left(T_{\mathrm{out}}-24\right) C D \\
P_{\mathrm{E}, \mathrm{c}, \mathrm{tot}}=P_{\mathrm{E}, \mathrm{c}, \mathrm{sol}}+P_{\mathrm{E}, \mathrm{c}, \mathrm{win}}+P_{\mathrm{E}, \mathrm{c}, \text { wall }}
\end{gathered}
$$

$P_{\mathrm{E}, \mathrm{c}, \mathrm{sol}}, P_{\mathrm{E}, \mathrm{c}, \mathrm{win}}, P_{\mathrm{E}, \mathrm{c}, \text { wall }}$ are the primary energy per unit area caused by solar heat gain and the heat gain through windows and walls, respectively. $P_{\mathrm{E}, \mathrm{c}, \text { tot }}$ is the total of these three primary energy demands over the cooling season. $\alpha_{n}, \beta_{n}, \gamma_{n}$ are constants that are calculated by applying the energy performance properties of the envelopes, according to the International Climate Zone, to the envelope properties, i.e., $A, F_{\mathrm{e}}, F_{\mathrm{sh}}, S H G C, U_{\text {win }}$ and $U_{\text {wall. }}$.

The primary energy per unit envelope area generated during the heating season can be expressed as below:

$$
\begin{gathered}
P_{\mathrm{E}, \mathrm{h}, \mathrm{sol}}=1.375 \alpha_{n} E_{\mathrm{tot}} H D \\
P_{\mathrm{E}, \mathrm{h}, \mathrm{win}}=1.375 \beta_{n}\left(T_{\text {out }}-18\right) H D
\end{gathered}
$$




$$
\begin{gathered}
P_{\mathrm{E}, \mathrm{h}, \text { wall }}=1.375 \gamma_{n}\left(T_{\mathrm{out}}-18\right) H D \\
\mathrm{P}_{\mathrm{E}, \mathrm{h}, \mathrm{tot}}=P_{\mathrm{E}, \mathrm{h}, \mathrm{sol}}+P_{\mathrm{E}, \mathrm{h}, \mathrm{win}}+P_{\mathrm{E}, \mathrm{h}, \text { wall }} \\
\left(\text { for } P_{\mathrm{E}, \mathrm{h}, \mathrm{sol}}<\left|P_{\mathrm{E}, \mathrm{h}, \mathrm{win}}+P_{\mathrm{E}, \mathrm{h}, \mathrm{wall}}\right|\right) \\
P_{\mathrm{E}, \mathrm{h}, \mathrm{tot}}=0, \quad\left(\text { for } P_{\mathrm{E}, \mathrm{h}, \mathrm{sol}} \geq\left|P_{\mathrm{E}, \mathrm{h}, \mathrm{win}}+P_{\mathrm{E}, \mathrm{h}, \mathrm{wall}}\right|\right)
\end{gathered}
$$

$P_{\mathrm{E}, \mathrm{h}, \mathrm{sol}}$ indicates the amount of effective solar heat gain, and $P_{\mathrm{E}, \mathrm{h} \text {,win }}$ and $P_{\mathrm{E}, \mathrm{h}, \text { wall }}$ are negative values expressing the heat loss by heat transmission through windows and walls. As per above, $P_{\mathrm{E}, \mathrm{h}, \text { tot }}$ is the sum of three primary energy demands. Note that it is assumed that there is no overheating when the effective solar heat gain is bigger than the heat loss; therefore, $P_{\mathrm{E}, \mathrm{h}, \text { tot }}$ cannot have a positive value.

The total annual primary energy through building envelopes is calculated by the sum of $P_{\mathrm{E}, \mathrm{c}, \mathrm{tot}}$ and $P_{\text {E,h,tot }}$ as follows:

$$
P_{\mathrm{E}, \mathrm{tot}}=P_{\mathrm{E}, \mathrm{c}, \mathrm{tot}}+\left|P_{\mathrm{E}, \mathrm{h}, \mathrm{tot}}\right|
$$

where,

$P_{\mathrm{E}, \text { tot }}:$ the total primary energy through building envelopes, $\mathrm{kWh} / \mathrm{m}^{2}$ year;

$\alpha_{n}, \beta_{n}, \gamma_{n}$ are governed by $S H G C, U_{\text {win }}$ and $U_{\text {wall }}$ of each climate zone. They vary depending on the properties of the governing parameters, which were derived from the International Climate Zones and ASHRAE Standard 90.1. Table 1 shows the values of $\alpha_{n}, \beta_{n}, \gamma_{n}$ in different zones.

Table 1. Calculated $\alpha_{n}, \beta_{n}, \gamma_{n}$ values based on International Climate Zones and the ASHRAE Standard. SHGC, solar heat gain coefficient.

\begin{tabular}{cccccccc}
\hline Zone Number & Climate Type & $\boldsymbol{S H G C}$ & $\boldsymbol{U}_{\text {win }}$ & $\boldsymbol{U}_{\text {wall }}$ & $\boldsymbol{\alpha}_{\boldsymbol{n}}$ & $\boldsymbol{\beta}_{\boldsymbol{n}}$ & $\boldsymbol{\gamma}_{\boldsymbol{n}}$ \\
\hline 1 & Very Hot & 0.25 & 6.81 & 3.293 & 0.002400 & 0.065376 & 0.047419 \\
2 & Hot & 0.25 & 4.26 & 0.857 & 0.002400 & 0.040896 & 0.012341 \\
3 & Warm & 0.25 & 3.69 & 0.701 & 0.002400 & 0.035424 & 0.010094 \\
4 & Mixed & 0.40 & 3.12 & 0.592 & 0.003840 & 0.029952 & 0.008525 \\
5 & Cool & 0.40 & 3.12 & 0.513 & 0.003840 & 0.029952 & 0.007387 \\
6 & Cold & 0.40 & 3.12 & 0.453 & 0.003840 & 0.029952 & 0.006523 \\
7 & Very Cold & 0.45 & 2.56 & 0.404 & 0.004320 & 0.024576 & 0.005818 \\
8 & Subarctic & 0.45 & 2.56 & 0.404 & 0.004320 & 0.024576 & 0.005818 \\
\hline
\end{tabular}

$F_{\mathrm{e}}: 40 \%, F_{\text {sh }}: 1$ (no shading).

\subsection{Development of $P$ and $S$ Indices}

The annual primary energy of the building envelopes is the sum of the primary energy consumed on cooling days and heating days. The ratio between these two can vary depending on the local climate conditions. For example, in the region where the cooling season is long and extreme, the heat gain through envelopes during this season becomes significantly bigger than the heat loss during the heating season. In order to effectively indicate the seasonal characteristics of the primary energy of both cooling and heating seasons, we defined the heating and cooling energy index " $P$ ", which is calculated by subtracting the primary heating energy from the primary cooling energy, then dividing it by the total primary energy, as shown below. The value of $P$ is between -1 and +1 . 


$$
P=\frac{P_{\mathrm{E}, \mathrm{c}, \mathrm{tot}}-\left|P_{\mathrm{E}, \mathrm{h}, \mathrm{tot}}\right|}{P_{\mathrm{E}, \mathrm{tot}}}
$$

Figure 2 shows the relative amount of primary energy during heating and cooling seasons. The closer $P$ gets to +1 , the bigger the primary energy demand of the building in the region will need to be during cooling days. Equally, the closer $P$ gets to -1 , the bigger the primary energy demand of the building will need to be during heating days. Where $P$ is near to null, the amount of primary heating energy is similar to the amount of primary cooling energy. In other words, the $P$ value is governed by the amount of heat gain and loss through the building envelope. For example, in the region where the amount of heat gain through the building envelope is significant, i.e., longer cooling days, $P$ will be close to +1 .

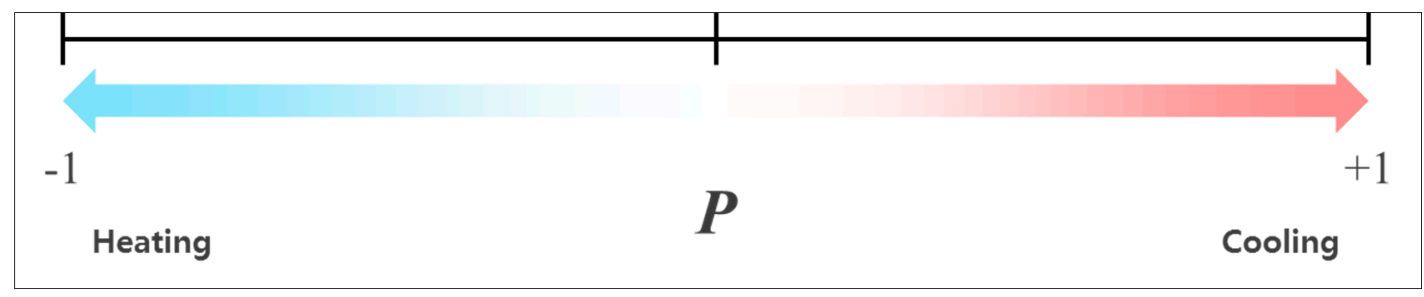

Figure 2. The range of the value of the heating and cooling energy index, $P$.

Solar radiation, which can potentially affect the heating and cooling energy demand, causes extra energy demand during cooling days, while it acts as an energy source by reducing the heating energy demand during heating days. The impact of solar radiation, however, can be minimised by improving the performance of shading devices, i.e., the shading factor, $F_{\text {sh. }}$ In particular, movable shading devices are effective, as they can actively adjust the amount of solar radiation coming through the building envelope. The impact of solar radiation through building envelopes can be assessed by carrying out a relative comparison between the heat gain of the envelopes during cooling days and the effective heat gain during heating days.

As the first step, the performance of the shading devices can be assessed by reviewing how much the heat gain during each season makes up of the total energy needed in that season. In some regions, however, the amounts of energy demand in each season can be significantly different from each other; therefore, it is necessary to convert this into the ratio between the total primary energy and the primary energy during heating and cooling days, which enables quantitative comparison of the effective heat gain in each season.

This can be expressed in the equations below:

$$
\begin{gathered}
S_{\mathrm{c}}=\left(\frac{P_{\mathrm{E}, \mathrm{c}, \mathrm{sol}}}{P_{\mathrm{E}, \mathrm{c}, \mathrm{sol}}+P_{\mathrm{E}, \mathrm{c}, \mathrm{win}}+P_{\mathrm{E}, \mathrm{c}, \text { wall }}}\right) \times \frac{P_{\mathrm{E}, \mathrm{c}, \mathrm{tot}}}{P_{\mathrm{E}, \mathrm{tot}}} \\
S_{\mathrm{h}}=\left(\frac{P_{\mathrm{E}, \mathrm{h}, \mathrm{sol}}}{\left|P_{\mathrm{E}, \mathrm{h}, \mathrm{win}}\right|+\left|P_{\mathrm{E}, \mathrm{h}, \mathrm{wall}}\right|}\right) \times \frac{P_{\mathrm{E}, \mathrm{h}, \mathrm{tot}}}{P_{\mathrm{E}, \mathrm{tot}}}, \quad\left(\text { for } P_{\mathrm{E}, \mathrm{h}, \mathrm{sol}}<\left|P_{\mathrm{E}, \mathrm{h}, \text { win }}+P_{\mathrm{E}, \mathrm{h}, \text { wall }}\right|\right) \\
S_{\mathrm{h}}=\frac{P_{\mathrm{E}, \mathrm{h}, \mathrm{tot}}}{P_{\mathrm{E}, \mathrm{tot}}}, \quad\left(\text { for } P_{\mathrm{E}, \mathrm{h}, \mathrm{sol}} \geq\left|P_{\mathrm{E}, \mathrm{h}, \mathrm{win}}+P_{\mathrm{E}, \mathrm{h}, \text { wall }}\right|\right)
\end{gathered}
$$

where,

$S_{\mathrm{c}}$ : the ratio of the solar heat gain on cooling days; 
$S_{\mathrm{h}}$ : the ratio of the solar heat gain on heating days.

The ratio of the heat gain over cooling days, $S_{\mathrm{c}}$, gets a value between zero and one. Where there is no heating season, i.e., the heat gain by solar radiation equals the total heat gain, $S_{\mathrm{c}}$ is one. Where there is no heat gain by solar radiation at all, $S_{\mathrm{c}}$ is zero. The closer $S_{\mathrm{c}}$ gets to one, the more necessary it is to control the solar radiation in that region.

The ratio of the effective heat gain over the heating season, $S_{\mathrm{h}}$, also gets a value between zero and one. Where there is no cooling season, i.e., the effective heat gain by solar radiation is equal to or greater than the heat loss through walls and windows, $S_{\mathrm{h}}$ is one. In this region, there is no primary energy during cooling days. The closer $S_{\mathrm{h}}$ gets to one, the bigger the effective heat gain of the building will be. Both $S_{\mathrm{c}}$ and $S_{\mathrm{h}}$ express the ratio of the heat gain by solar radiation during cooling and heating days. The ratio of $S_{\mathrm{c}}$ and $S_{\mathrm{h}}$ cannot be one, unless the heat transfer generated by the temperature difference between the indoors and outdoors is zero.

The information about the characteristics of the heat gain described by $S_{\mathrm{c}}$ and $S_{\mathrm{h}}$ can also be interpreted as the feasibility of implementing shading devices. It can be stated that the closer $S_{\mathrm{c}}$ gets to one and $S_{\mathrm{h}}$ to zero, the more beneficial it is to install shading devices on the building in that region. Where $S_{\mathrm{c}}$ is near to zero and $S_{\mathrm{h}}$ to one, the heat gain by solar radiation during the cooling season is low and the effective heat gain during the heating season is high; therefore, it may not be necessary to install shading devices. Where $S_{\mathrm{c}}$ and $S_{\mathrm{h}}$ obtain similar values, the heat gains in each season are similar to each other; therefore, movable shading devices may be recommended. In order to comparatively evaluate the heat gains over cooling and heating seasons, we defined the solar heat gain index " $S$ ", which is calculated by subtracting $S_{\mathrm{h}}$ from $S_{\mathrm{c}}$, as shown below. The value of $S$ is between -1 and +1 .

$$
S=S_{\mathrm{c}}-S_{\mathrm{h}}
$$

If $S$ is close to +1 , this means that the solar heat gain on cooling days is much bigger than the effective heat gain on heating days. Fixed shading devices, therefore, are recommended in this region.

Table 2 shows the recommendations on shading type depending on the value of $S$, which has a value between -1 and +1 . The closer $S$ gets to +1 , i.e., $F_{\text {sh }}$ decreases, the better it is to improve the shading performance. On the contrary, when $S$ gets near to zero, it is necessary to adjust $F_{\text {sh. Where }} S$ is near to -1 , shading devices are not feasible. The range of $S$ for each shading type is not definitive and can vary depending on the shading type.

Table 2. Solar heat gain index, $S$.

\begin{tabular}{ccc}
\hline Index $\boldsymbol{S}$ & Shading Requirement & Recommended Shading Type \\
\hline Close to 1 (suggested range, $S \geq 0.5$ ) & Strong & Fixed (or Movable) \\
Close to 0 (suggested range, $-0.5<S<0.5$ ) & Medium & Movable \\
Close to -1 (suggested range, $S \leq-0.5$ ) & Weak & None \\
\hline
\end{tabular}

\section{Application of Climate Indices}

In this section, the values of $P$ and $\mathrm{S}$ were derived for 24 regions (see Table 3), which represent various local climate conditions. The United States was selected as the model area, since it contains all eight climate zones described in the International Climate Zone [24]. Three cities from each climate zone were chosen such that the cities to assess are reasonably distant from each other, representing the 
climate of that region. The directional data (east, south, west and north) of each city were obtained from the Meteonorm7 [25] tool, which was used to derive the indices.

Table 3. $P$ and $S$ values of 24 target cities.

\begin{tabular}{|c|c|c|c|c|c|c|c|c|c|c|c|c|c|}
\hline \multirow{2}{*}{\multicolumn{2}{|c|}{$\begin{array}{c}\text { International Climate } \\
\text { Zone, } n\end{array}$}} & \multirow{2}{*}{$\begin{array}{l}\text { Latitude } \\
\text { (Degree) }\end{array}$} & \multirow{2}{*}{$\begin{array}{c}P_{E, \text { tot }} \\
(\mathbf{k W h})\end{array}$} & \multicolumn{2}{|c|}{$\mathbf{E}$} & \multicolumn{2}{|c|}{$\mathbf{S}$} & \multicolumn{2}{|c|}{ W } & \multicolumn{2}{|c|}{$\mathbf{N}$} & \multicolumn{2}{|c|}{ Average } \\
\hline & & & & $\boldsymbol{P}$ & $S$ & $\boldsymbol{P}$ & $S$ & $\boldsymbol{P}$ & $S$ & $\boldsymbol{P}$ & $S$ & $P$ & $S$ \\
\hline \multirow{3}{*}{1} & Honolulu Oahu, HI & 21.3 & 127.2 & 1.0 & 0.6 & 1.0 & 0.5 & 1.0 & 0.6 & 1.0 & 0.4 & 1.0 & 0.5 \\
\hline & Key West, FL & 24.6 & 159.2 & 1.0 & 0.4 & 1.0 & 0.4 & 1.0 & 0.4 & 1.0 & 0.3 & 1.0 & 0.4 \\
\hline & Miami, FL & 25.8 & 134.6 & 1.0 & 0.5 & 1.0 & 0.4 & 1.0 & 0.4 & 0.9 & 0.3 & 1.0 & 0.4 \\
\hline \multirow{3}{*}{2} & Austin, TX & 30.3 & 94.4 & 0.4 & 0.3 & 0.8 & 0.4 & 0.4 & 0.3 & 0.0 & 0.1 & 0.4 & 0.3 \\
\hline & Jackson, MS & 32.3 & 84.6 & 0.1 & 0.2 & 0.6 & 0.3 & 0.1 & 0.2 & -0.3 & 0.0 & 0.1 & 0.2 \\
\hline & Phoenix, AZ & 33.4 & 140.7 & 1.0 & 0.5 & 1.0 & 0.4 & 1.0 & 0.5 & 0.7 & 0.2 & 0.9 & 0.4 \\
\hline \multirow{3}{*}{3} & Atlanta, GA & 33.7 & 64.7 & 0.0 & 0.1 & 1.0 & 0.7 & 0.0 & 0.1 & -0.5 & -0.0 & 0.1 & 0.2 \\
\hline & Oklahoma, OK & 35.4 & 94.8 & -0.1 & 0.0 & 0.4 & 0.2 & -0.1 & 0.0 & -0.5 & -0.0 & -0.1 & 0.1 \\
\hline & San Francisco, CA & 37.6 & 10.4 & 1.0 & 0.9 & 1.0 & 0.9 & 1.0 & 1.0 & -1.0 & -0.6 & 0.5 & 0.6 \\
\hline \multirow{3}{*}{4} & Columbia, MO & 38.8 & 66.2 & -0.0 & 0.0 & 1.0 & 0.8 & -0.0 & 0.0 & -0.7 & -0.2 & 0.1 & 0.2 \\
\hline & New York City, NY & 40.8 & 63.7 & 0.1 & 0.1 & 1.0 & 0.8 & 0.1 & 0.1 & -0.6 & -0.2 & 0.1 & 0.2 \\
\hline & Seattle, WA & 47.5 & 20.4 & 0.3 & 0.2 & 1.0 & 0.9 & -0.4 & -0.4 & -1.0 & -0.5 & -0.0 & 0.1 \\
\hline \multirow{3}{*}{5} & Cleveland, $\mathrm{OH}$ & 41.4 & 69.5 & -0.5 & -0.3 & 0.2 & 0.2 & -0.6 & -0.3 & -0.8 & -0.3 & -0.4 & -0.2 \\
\hline & Denver, $\mathrm{CO}$ & 39.8 & 54.8 & -0.0 & -0.0 & 1.0 & 0.9 & -0.0 & -0.0 & -0.8 & -0.3 & 0.0 & 0.1 \\
\hline & Tonopah, NV & 38.6 & 49.0 & 1.0 & 0.9 & 1.0 & 0.9 & 1.0 & 0.9 & -0.7 & -0.2 & 0.6 & 0.6 \\
\hline \multirow{3}{*}{6} & Bangor, ME & 44.8 & 82.7 & -0.9 & -0.6 & -0.8 & -0.7 & -0.9 & -0.6 & -1.0 & -0.3 & -0.9 & -0.6 \\
\hline & Green Bay, WI & 44.5 & 76.3 & -0.8 & -0.5 & 0.6 & 0.5 & -0.8 & -0.5 & -0.9 & -0.3 & -0.5 & -0.2 \\
\hline & Helena, MT & 46.6 & 72.6 & -0.6 & -0.4 & 1.0 & 0.9 & -0.6 & -0.4 & -0.9 & -0.3 & -0.3 & -0.0 \\
\hline \multirow{3}{*}{7} & Anchorage, AK & 61.2 & 70.3 & -1.0 & -0.7 & 0.0 & 0.0 & -1.0 & -0.7 & -1.0 & -0.3 & -0.8 & -0.4 \\
\hline & Houghton, MI & 44.4 & 36.7 & -0.7 & -0.6 & 1.0 & 0.9 & -0.7 & -0.6 & -1.0 & -0.4 & -0.3 & -0.2 \\
\hline & Roseau, MN & 48.9 & 75.1 & -0.7 & -0.5 & -0.8 & -0.8 & -0.7 & -0.6 & -0.9 & -0.3 & -0.8 & -0.6 \\
\hline \multirow{3}{*}{8} & Bethel, AK & 60.8 & 93.8 & -1.0 & -0.7 & 0.0 & 0.0 & -1.0 & -0.7 & -1.0 & -0.3 & -0.8 & -0.4 \\
\hline & Bettles, AK & 66.9 & 165.8 & -1.0 & -0.5 & -1.0 & -0.7 & -1.0 & -0.5 & -1.0 & -0.3 & -1.0 & -0.5 \\
\hline & Nome, AK & 64.5 & 130.3 & -1.0 & -0.6 & -1.0 & -0.8 & -1.0 & -0.6 & -1.0 & -0.3 & -1.0 & -0.6 \\
\hline
\end{tabular}

Figure 3 indicates a map to show the pattern of the $P$ index based on the International Climate Zone. The average of $P$ values for four directions was used as the representative value of each city. All regions in the United States, including Hawaii and Alaska, were located between 20 and 70 degrees latitude. In general, the $P$ index gets closer to one as the city is located at lower degrees of latitude, and to -1 at higher degrees. The cities located between 30 and 40 degrees latitude had $P$ near zero. Tonopah (Zone 5) and Columbia (Zone 4), however, had different $P$ values, even though they were located at the same degree latitude, and this could be seen from other cities, as well, which are located at similar degrees of latitude.

It was also revealed that the cities in Zone 1 and Zone 8 had similar values of $P$; however, the indices of the cities in Zones 2 to 7, except Zone 4, varied by 0.5 up to 1.0, even when the cities were in the same zone. Additionally, $P_{\mathrm{E}, \text { tot }}$ (the average value of directional primary energy demand) also varied between the cities in the same International Climate Zone and showed a wide range of values. San Francisco $(P=+0.5)$ had the smallest $P_{\mathrm{E}, \text { tot }}$ of $10.4 \mathrm{kWh} / \mathrm{m}^{2}$ year, while Bettles $(P=-1.0)$ had the biggest value of $165.8 \mathrm{kWh} / \mathrm{m}^{2}$ year. 


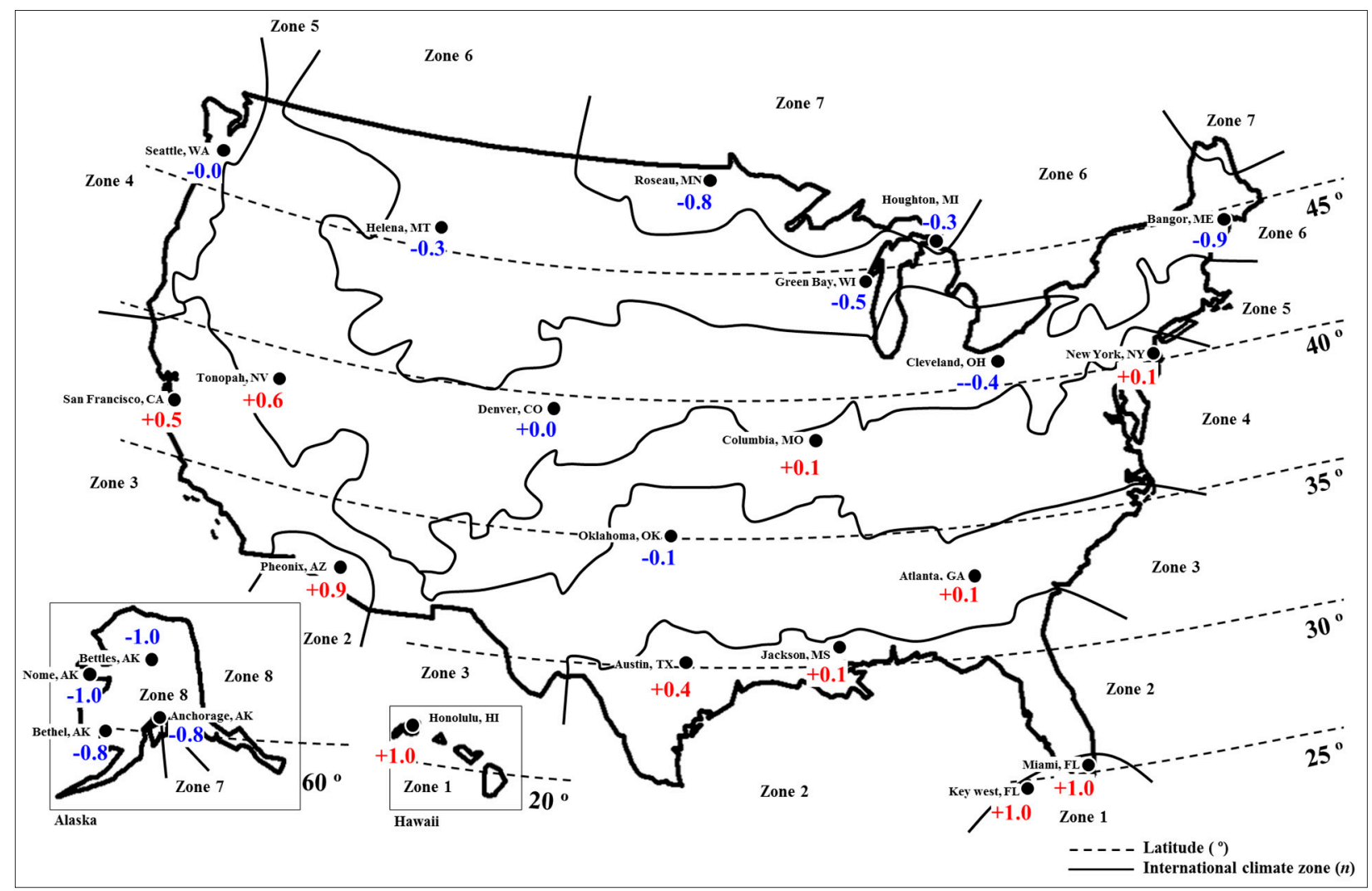

Figure 3. Map showing the values of $P$ of 24 cities in different climate zone in the U.S.

Figure 4 presents the values of $P$ and $S$ in order to describe the characteristics of the regional climate index. The horizontal axis of the graph represents the value of $P$, and the vertical axis shows the value of index $S$. The average of the $P$ and $S$ values of each city, as well as the directional $S$ values were plotted on the graph. Three cities in Zone 1 and some other cities in Zones 2, 3 and 5 had a $P$ value near +1 . These cities are located in the region where the amount of energy of the building envelopes during cooling days is relatively bigger. The cities in Zones 6, 7 and 8 had a $P$ value close to -1 , which means that the amount of energy of the envelopes during heating days is relatively bigger in these areas. The values of $P$ for the rest of the twelve cities were close to zero, meaning that the primary energy of the envelopes during heating and cooling days is similar.

The average of directional $S$ values were similar to the $P$ values, thus they seem to be proportional to each other. However, when the ranges of directional $S$ values are compared, they varied by 0.1 up to 1.6, for which, in other words, the required shading performance varies depending on the direction. When the values of $S$ were reviewed against the values of $P, S$ was relatively lower in most of the cities where the $P$ values were smaller than -0.5 . In Bethel and Anchorage, on the contrary, $S$ values were near zero. Directional $S$ values did not vary much, and they were close to 0.5 in four cities, including Key West, where $P$ was above 0.5. In these cities, shading devices are recommended in all directions. In San Francisco and Tonopah, the $S$ values of east, west and south seem to be significantly different from the value of north. For the east, west and south directions in these cities, solar radiation should be controlled, as the heat gain during cooling days is much bigger than the effective heat gain during heating days. The $S$ values for north, however, seem to be low in both cities. In the rest of twelve cities where the $P$ values were between -0.5 and $+0.5, S$ varied significantly. For eight cities, 
including Green Bay, the $S$ value for south was higher than 0.5 , and therefore, fixed shading devices are recommended in these cities. The $S$ values of other directions, i.e., east, west and north, varied.

By analysing the indices, $P$ and $S$, it was clearly shown that even if the cities were located in the same International Climate Zone with a similar latitude, the required performance of the shading devices can vary based on the directions. An example may describe the practical use of the indices, $P$ and $S$. An architect who designs buildings located in Green Bay, Helena and Houghton carries out a brief study on the local climate conditions and gets values of $P$ and $S$ in those areas. The architect then would know that fixed shading devices are recommended and would know that fixed shading devices are recommended for the east, west and south side of the buildings located in San Francisco and Tonopah and for the east and west side of the buildings located in Honolulu, Oahu.

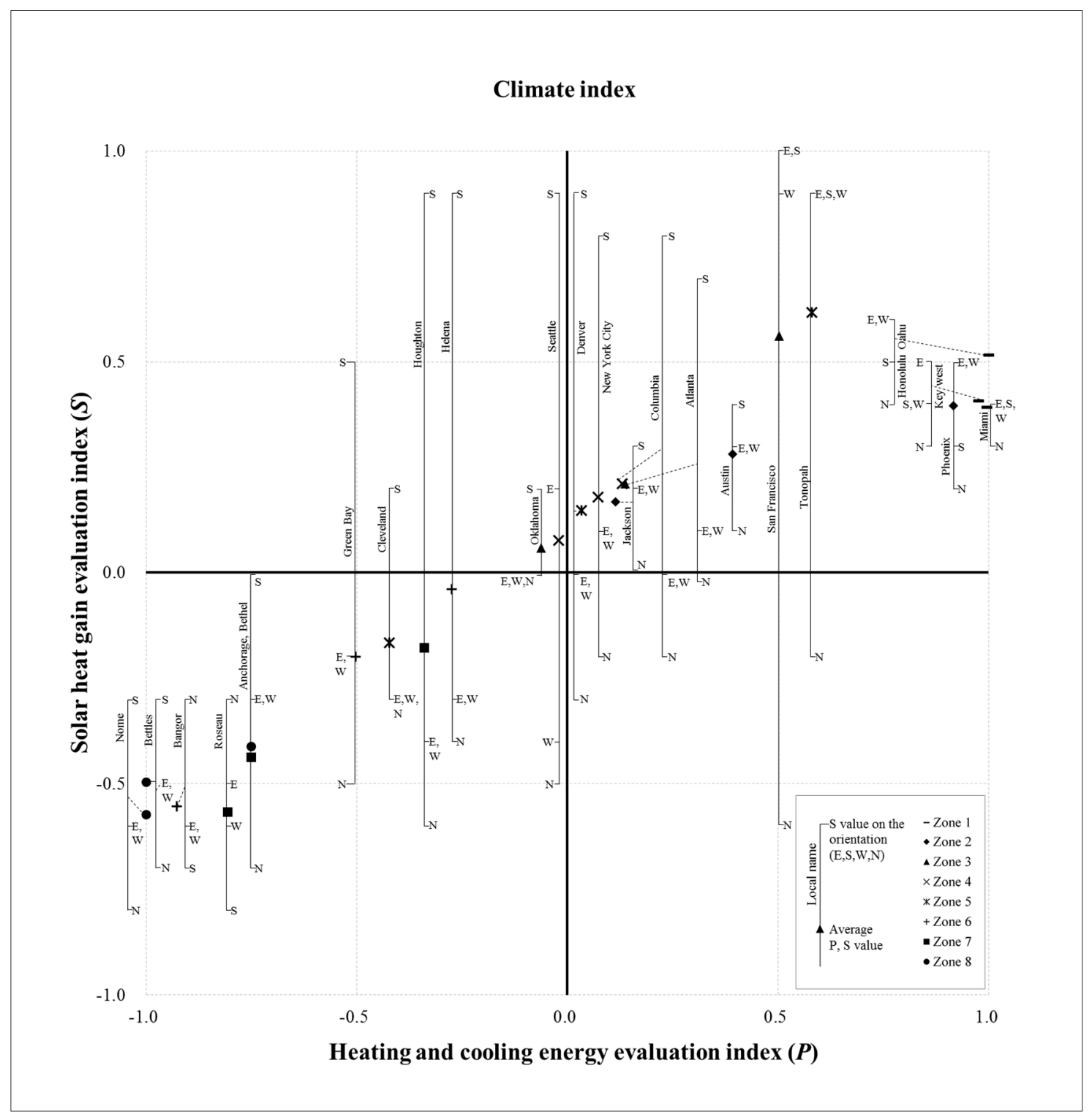

Figure 4. Graph showing the values of $P$ and $S$ for four directions in 24 cities of eight Climate Zones in the U.S. 


\section{Conclusions}

The climate indices $P$ and $S$ were developed in order to carry out a relative evaluation of the cooling and heating energy demands and solar gains considering the regional climate conditions. $P$ enables the relative evaluation of the amount of energy required over heating and cooling days in terms of primary energy, and it indicates the characteristics of the local climate conditions. $S$, on the other hand, is used for comparing the solar heat gain during cooling days with effective heat gain during heating days, thus indicating the characteristics of the local climate from the solar radiation aspect. In order to develop the climate indices, regional climate data were used, and the parameters related to building envelopes were fixed. Daily average solar irradiance and ambient temperature were used as the key climate elements, and building envelopes were defined according to the eight categories of the International Climate Zone described in ASHRAE 90.1. The values of $P$ and $S$ for four directions, i.e., east, south, west and north, in 24 cities were derived, and the average of the $P$ values of all directions was considered as the representative value.

It was shown that the value of $P$ can vary up to 0.5 , even if the cities related to these values are in the region with the same latitude, and up to 1.0, even when the region was part of the same International Climate Zone. By plotting the values of $P$ and $S$ of 24 cities on a graph, it was shown that $P$ and $S$ are fairly proportional to each other and that six regions had relatively small $P$ and $S$, while six other regions had big values; the rest of the 12 regions had values in the middle. By investigating the values of $P$ and $S$ of 24 cities, it was possible to carry out qualitative assessments of the heating and cooling energy demands in those regions, enabling a review of the performance of the shading devices.

The International Climate Zone provided details of the local climate conditions around the globe, and ASHRAE 90.1 can help users to establish a model building in each climate zone. Although it was not included in this paper, the methodology described in this paper can potentially be applied to other regions around the world. The indices, $P$ and $S$, therefore, can be useful tools for designers and engineers to carry out quantitative assessment of the local climate conditions and the characteristics of solar radiation, enabling them to make judgments on the installation of shading devices at the early design stage.

\section{Acknowledgments}

This work was supported by the World Class 300 Project (No. 10046952) funded by the Small \& Medium Business Administration in the Republic of Korea.

\section{Author Contributions}

Jae-Hun Jo had the original idea for the study, and all co-authors conceived of and designed the methodology. Dong-Seok Lee and Sung-Han Koo drafted the manuscript, which was revised by Jae-Hun Jo. All authors read and approved the final manuscript.

\section{Nomenclature}

$q_{\mathrm{c} \text {, sol }}$ : Heat transfer by solar radiance through windows on cooling days, $\mathrm{kWh}$

$q_{\mathrm{h} \text {, sol }}$ : Heat transfer by solar radiance through windows on heating days, $\mathrm{kWh}$

$q_{\mathrm{h}, \text { win }}$ : Conductive heat transfer through windows on heating days, $\mathrm{kWh}$ 
$q_{c, \text { win }}$ : Conductive heat transfer through windows on cooling days, $\mathrm{kWh}$

$q_{h \text {,wall }}$ : Conductive heat transfer through walls on heating days, kWh

$q_{c, \text { wall }}$ : Conductive heat transfer through walls on cooling days, $\mathrm{kWh}$

$A$ : Wall area, $\mathrm{m}^{2}$

$F_{\mathrm{e}}$ : Glazing ratio

$U_{\text {wall }}$ : Thermal transmittance of walls, $\mathrm{W} / \mathrm{m}^{2} \mathrm{~K}$

$U_{\text {win }}$ : Thermal transmittance of windows, $\mathrm{W} / \mathrm{m}^{2} \mathrm{~K}$

$E_{\text {tot }}$ : Average solar irradiance for an hour on the facade plane, $\mathrm{W} / \mathrm{m}^{2}$

$S H G C$ : Solar heat gain coefficient

$F_{\text {sh }}$ : Shading factor

$C D, H D$ : Number of days for cooling and heating modes

$T_{\text {out }}$ : Outdoor temperature, ${ }^{\circ} \mathrm{C}$

$T_{\text {in }}$ : Indoor temperature, ${ }^{\circ} \mathrm{C}$

\section{Conflicts of Interest}

The authors declare no conflicts of interest.

\section{References}

1. Choi, J.J.; Jung, J.M.; Song, S.Y. A study on the climatic design process with climate characteristics data-Focused on Seoul. J. Archit. Inst. Korea 2001, 21, 841-844.

2. Masson, V.; Marchadier, C.; Adolphe, L.; Aguejdad, R.; Avner, P.; Bonhomme, M.; Bretagne, G.; Briottet, X.; Bueno, B.; de Munck, C.; et al. Adapting cities to climate change: A systemic modelling approach. Urban Clim. 2014, 10, 407-429.

3. $\mathrm{Su}, \mathrm{X}$; Z Zhang, X. Environmental performance optimization of window-wall ratio for different window type in hot summer and cold winter zone in China based on life cycle assessment. Energy Build. 2010, 42, 198-202.

4. Battista, G.; Evangelisti, L.; Guattari, C.; Basilicata, C.; de Lieto Vollaro, R. Buildings energy efficiency: Interventions analysis under a smart cities approach. Sustainability 2014, 6, 4694-4705.

5. Choi, J.P.; Lee, T.K.; Ahn, E.S.; Piao, G.S.; Lim, J.H. An evaluation system for parametric exterior louver designs including physical surroundings. J. Archit. Inst. Korea 2013, 29, 91-98.

6. Kim, G.; Lim, H.S.; Lim, T.S.; Schaefer, L.; Kim, J.T. Comparative advantage of an exterior shading device in thermal performance for residential buildings. Energy Build. 2012, 46, 105-111.

7. Freewan, A.A.Y. Impact of external shading devices on thermal and daylighting performance of offices in hot climate regions. Sol. Energy 2014, 102, 14-30.

8. David, M.; Donn, M.; Garde, F.; Lenoir, A. Assessment of the thermal and visual efficiency of solar shades. Build. Environ. 2011, 46, 1489-1496.

9. Fiocchi, C.; Hoque, S.; Shahadat, M. Climate responsive design and the milam residence. Sustainability 2011, 3, 2289-2306.

10. Tzempelikos, A.; Shen, H. Comparative control strategies for roller shades with respect to daylighting and energy performance. Build. Environ. 2013, 67, 179-192. 
11. Kim, S.H.; Kim, S.S.; Kim, K.W.; Cho, Y.H. A study on the proposes of energy analysis indicator by the window elements of office buildings in Korea. Energy Build. 2014, 73, 153-165.

12. Carletti, C.; Sciurpi, F.; Pierangioli, L. The energy upgrading of existing buildings: Window and shading device typologies for energy efficiency refurbishment. Sustainability 2014, 6, 5354-5377.

13. Picco, M.; Lollini, R.; Marengo, M. Towards energy performance evaluation in early stage building design: A simplification methodology for commercial building models. Energy Build. 2014, 76, 497-505.

14. Baker, N.; Steemers, K. LT Method 3.0-A strategic energy-design tool for Southern Europe. Energy Build. 1996, 23, 251-256.

15. Kumar, B.; Emmanuel, R. Independent Verification of a Climate-Based Worldwide Building Energy Index; Glasgow Caledonian University: Glasgow, UK, 2010; pp. 1-13.

16. McLean, D.; Roderick, Y.; Quincey, R.; McEwan, D. Climate energy index and building energy index: New indices to assess and benchmark building energy performance. In Proceedings of the Building Simulation 12th Conference of International Building Performance Simulation Association, Sydney, Australia, 14-16 November 2011; pp. 792-799.

17. CIBSE. Degree-Days: Theory and Application; CIBSE: London, UK, 2006; pp. 1-106.

18. Pisello, A.L.; Santamouris, M.; Cotana, F. Active cool roof effect: Impact of cool roofs on cooling system efficiency. Adv. Build. Energy Res. 2013, 7, 209-221

19. Georgakis, C.; Zoras, S.; Santamouris, M. Studying the effect of "cool" coatings in street urban canyons and its potential as a heat island mitigation technique. Sustain. Cities Soc. 2014, 13, $20-31$.

20. ISO 18292. Energy Performance of Fenestration Systems for Residential Buildings-Calculation Method; ISO: Geneva, Switzerland, 2011; pp. 1-32.

21. Perez-Lombard, L.; Ortiz, J.; Maestre, I.R. The map of energy flow in HVAC systems. Appl. Energy 2011, 88, 5020-5031.

22. Perez-Lombard, L.; Ortiz, J.; Maestre, I.R.; Coronel, J.F. Constructing HVAC energy efficiency indicators. Energy Build. 2012, 47, 619-629.

23. Baker, N.; Steemers, K. Energy and Environment in Aichitecture-A Technical Design Guide; Taylor \& Francis: London, UK, 2005; pp. 2-118.

24. ASHRAE Standard 90.1. Energy Standard for Buildings Except Low-Rise Residential Buildings; ASHRAE: Atlanta, GA, USA, 2007; pp. 19-28.

25. Meteonorm. Available online: http://meteonorm.com/ (accessed on 22 September 2014).

(C) 2015 by the authors; licensee MDPI, Basel, Switzerland. This article is an open access article distributed under the terms and conditions of the Creative Commons Attribution license (http://creativecommons.org/licenses/by/4.0/). 